\title{
Estimación de la fracción de la mortalidad en Rusia atribuible al alcohol
}

\section{Estimation of alcohol attributable fraction of mortality in Russia}

| YuRY E. RaZVODOVSKY
| Grodno State Medical University

\section{Resumen}

La evidencia acumulada sugiere que el alcohol contribuye de forma importante a la cifra total de muertes prematuras en Rusia. El objetivo del presente estudio fue estimar la mortalidad adulta prematura atribuible al abuso de alcohol en Rusia sobre la base de datos a nivel agregado de todas las causas de mortalidad y de consumo de alcohol. Con este propósito se analizaron los datos de mortalidad por cualquier causa para el periodo 1980-2005 estandarizados por edad y por sexo junto con los datos sobre el consumo global de alcohol mediante series temporales ARIMA. Como resultado de la comparación, se encontró que el consumo de alcohol se asociaba significativamente con todas las causas de mortalidad masculina y femenina: un aumento de 1 litro en el consumo global de alcohol se traduciría en un aumento del 3,9\% en la tasa de mortalidad masculina y en un $2,4 \%$ de aumento en la tasa de mortalidad femenina. Los resultados del análisis también indican que el $41,1 \%$ de las defunciones de hombres y el $27,8 \%$ las muertes de mujeres en Rusia podria atribuirse al alcohol. Podemos concluir que el alcohol es un importante contribuyente a la alta tasa de mortalidad en la Federación de Rusia. Por lo tanto la prevención de daños atribuibles al alcohol debe ser una prioridad de salud pública en Rusia.

Palabras clave: mortalidad, consumo de alcohol, Rusia.

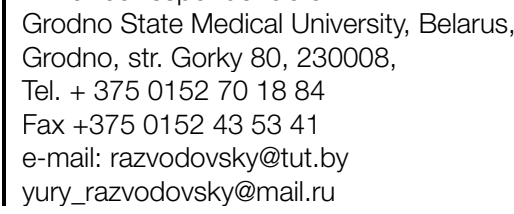

\section{Abstract}

Accumulated research evidence suggests that alcohol is a major contributor to premature deaths toll in Russia. The aim of the present study was to estimate the premature adult mortality attributable to alcohol abuse in Russia on the basis of aggregate-level data of allcause mortality and alcohol consumption. With this purpose agestandardized sex-specific male and female all-cause mortality data for the period 1980-2005 and data on overall alcohol consumption were analyzed by means ARIMA time series analysis. As a result alcohol consumption was significantly associated with both male and female all-cause mortality rates: a 1 liter increase in overall alcohol consumption would result in a $3.9 \%$ increase in the male mortality rate and in $2.4 \%$ increase in female mortality rate. The results of the analysis also suggest that $41.1 \%$ of all male deaths and $27.8 \%$ female deaths in Russia could be attributed to alcohol. We can conclude that alcohol is a major contributor to the high mortality rate in Russian Federation. Therefore prevention of alcohol-attributable harm should be a major public health priority in Russia.

Key words: mortality, alcohol drinking, alcohol attributable fraction, Russia. 
The harmful use of alcohol was identified as one of the major contributing factor to mortality globally (WHO 2011). Alcohol consumption caused a considerable disease burden in Europe: $6,1 \%$ of all the deaths could be attributed to this factor, with most of the burden in Eastern European region (Anderson, \& Baumberg, 2006; Moskalewicz, Razvodovsky, $\&$ Wieczorek, 2009). According to the estimates alcohol consumption is responsible for $13.6 \%$ of premature mortality cases among men aged 20 to 64 years in Poland; this figure is $16.3 \%$ in the Czech Republic, 22.8\% in Lithuania, and 25.2\% in Hungary (Rehm, Taylor, \& Patra, 2006). Its contribution is especially striking in Russia, where alcohol may be responsible for more than 30\% of all deaths (Nemtsov, 2002). A systematic analysis of alcohol-attributable mortality burden undertaken by a group of international experts showed that in Russia alcohol was responsible for 17,9\% of all premature deaths in men and 8,5\% in women (Rehm, et al., 2007). However, the authors acknowledge that this figure could be underestimated, as several disease categories were not included because of the different classification system of disease in Russia and the respective degree of underestimation could amount to 20,6\% for men and 30,9\% for women. The highest proportion of alcohol-attributable deaths was found in the age group 20-44 years $(30,7 \%$ in men and 19,9\% in women) (Rehm et al., 2007). Collectively, this research evidence suggests that alcohol is a major contributor to premature deaths toll in Russia.

The calculation of alcohol-attributable mortality currently is routinely applied to provide an indication of the public health effect of harmful alcohol consumption for developing strategy to prevent alcohol-related mortality (Murray, Ezzati, Lopez, Rodgers, \& Hoorn, 2003). The alcohol-attributable fraction (AAF) is generally defined as the proportion of the disease in the population that would not occur if lifetime exposure to alcohol were hypothetically changed to the counterfactual level of zero (Murray et al., 2003).

Overall, the cause-specific approach may provide greater confidence than the all-cause approach with regard to the relationship between alcohol consumption and mortality. However, AAF estimates based on this methodology have several limitations and require a number of assumptions to be made. In particular, the calculation is a function of relative risk and population drinking estimates, and therefore relies on the accuracy of estimates of alcohol consumption and the relative risk estimates reported in the epidemiological literature. It is acknowledge, however, that self-reported alcohol consumption is usually greatly underestimated (Alanko, 1984). Further, alcohol-related risk is associated with two dimensions of alcohol: average volume of alcohol consumption as well as pattern of drinking, although most of epidemiological studies have not examined the impact of drinking pattern (Grant \& Litvak, 1998). At the same time, there is convincing evidence that irregular heavy drinking may increase the risk of mortality (Stickley et al, 2007). In addition, some alcoholrelated conditions are not covered by epidemiological studies and, therefore, omitted. This is especially true for Russia where there is a large degree of misclassification and many deaths which should be attributable to alcohol are actually coded as other deaths (mainly external and cardiovascular) leading to a severe underestimation of the impact of alcohol as a risk factor (Andreev, Pridemore, Shkolnikov, \& Antonova, 2007). Given these limitations, the figures derived using this methodology is likely to be an underestimation of the deaths attributable to hazardous alcohol consumption.

Swedish researcher T. Norstrom has suggested that aggregate data may be used for estimation of alcoholattributable mortality and developed method for AAF estimation based on time series analysis of all-causemortality rate and the level of overall alcohol consumption using ARIMA time series analysis (Norström, 1989). It was shown that the effect of alcohol on alcohol-related mortality estimated from time series data was consistent with the corresponding ecological estimates (Norström, 1989).

Aggregate-level studies usually report a significant and positive relationship between alcohol consumption and allcause mortality (Norström, 2001; Norström \& Razvodovsky, 2010). The link between mortality and population drinking in Russia has been analyzed in a number of aggregate-level studies. Nemtsov has reported that 1 liter increase in alcohol consumption is expected to increase mortality by $3.6 \%$ for the total population (5.9\% for men and 1.9\% for women) ( Nemtsov, 2002). A more recent update suggests that there was a statistically significant alcohol effect in Russia between 1960 and 1998, implying that a 1-litre increase in alcohol consumption would result in $2.7 \%$ increase in male mortality (Norström, 2006). So, previous researches have shown that a strong relationship exists between per capita consumption of alcohol and all-cause mortality in Russia.

However, when trying to assess the impact of per capita alcohol consumption on mortality rate it is important to have accurate consumption figures. This is particularly difficult in Russia, where considerable proportion of alcohol came from illicit sources and the results of previous estimates of population drinking are highly questionable (Razvodovsky, 2008). A potential limitation of previous Russian estimates of alcohol consumption is that they have relied upon alcoholrelated mortality (Nemtsov, 2000; Razvodovsky, 2010a). This implies that the alcohol effects estimates might be spurious. Therefore, we assume that the incidence rate of alcohol psychoses may better capture the aggregate level of alcohol consumption than official sales statistics and previous expert estimation. This assumption is consistent with the findings, which suggest that the incidence rate of alcohol psychoses is among the most consistent predictors of the rate of alcoholrelated problems in Russia (Nemtsov, \& Razvodovsky, 2008).

The aim of the present study was to estimate the premature adult mortality attributable to alcohol abuse in Russia using aggregate-level data of all-cause mortality and estimates of overall level of alcohol consumption from 1980 to 2005 .

\section{Method}

The data on age-adjusted sex-specific all-cause mortality rates per 1000.000 of residents (age 15+) are taken from 
the Russian vital statistics registration system. The overall level of alcohol consumption in Russia has been estimated using the indirect method based on alcohol psychoses incidence rate and employing the autoregressive integrated moving average (ARIMA) model. This method is based on the difference between the observed level of alcohol-related harm and level estimated from recorded alcohol consumption (Razvodovsky, 2010a).

To examine the relation between alcohol consumption and all-cause mortality ARIMA time-series analysis was performed using the statistical package "Statistica" (StatSoft). The dependent variables were the all-cause mortality rates and the independent variable was aggregate overall alcohol consumption. Bivariate correlations between the raw data from two time-series can often be spurious due to common sources in the trends and due to autocorrelation (Norstrom, \& Skog 2001). One way to reduce the risk of obtaining a spurious relation between two variables that have common trends is to remove these trends by means of a 'differencing' procedure, as expressed in formula:

$$
\nabla x_{t}=x_{t}-x_{t-1}
$$

This means that the annual changes ' $\tilde{N}$ ' in variable ' $X$ ' are analyzed rather than raw data. The process whereby systematic variation within a time series is eliminated before the examination of potential causal relationships is referred to as 'prewhitening. This is subsequently followed an inspection of the cross-correlation function in order to estimate the association between the two prewhitened time series. It was Box and Jenkins (Box, \& Jenkins, 1976) who first proposed this particular method for undertaking a time series analysis and it is commonly referred to as ARIMA (autoregressive integrated moving average) modelling. As a large fraction of alcohol-related mortality has an exponential risk function, a semi-logarithmic model with logged output series was used to estimate the relationship between allcause mortality and alcohol consumption in this paper.

According to the method suggested by Norström AAF can be calculated from the estimates obtained in ARIMA models according to following formula: $A A F=1-\exp (-b X)$, were $X$ is average level of alcohol consumption for the period under analysis and b- estimate derived from ARIMA time series analysis (Norström, 1989).

\section{Results}

The trends in the age-adjusted, sex-specific all-cause mortality rates and estimates of overall level of alcohol consumption are displayed in Figures 1-2. The graphical evidence suggests that the trends in both all-cause mortality and alcohol consumption per capita for males and females seem to follow each other across the time-series. As can be seen from Figures there were sharp trends in the time series data across the study period. These trends were removed by means of a first-order differencing procedure.

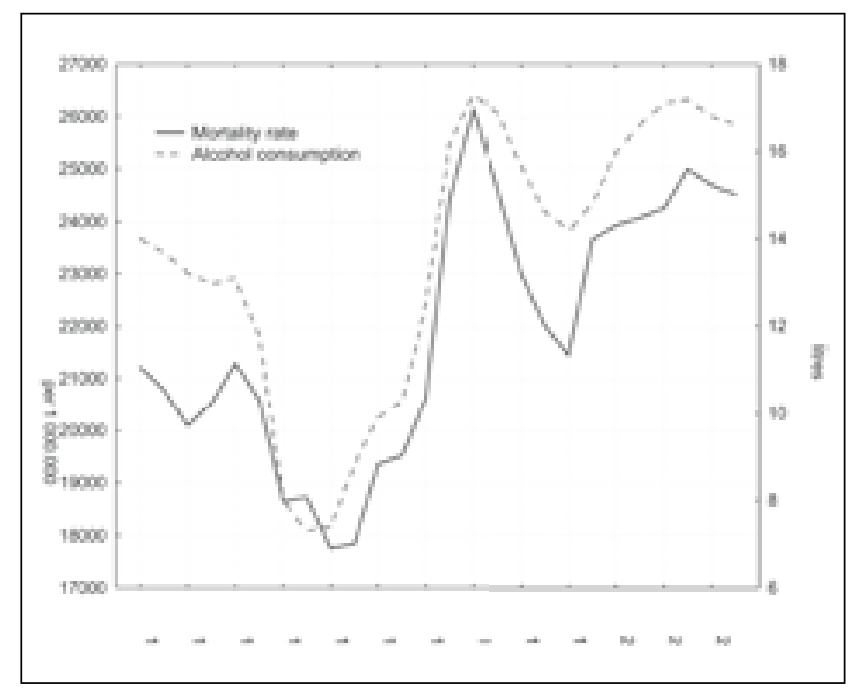

Figure 1. Trends in male all-cause mortality rate (right scale) and alcohol consumption per capita (left scale) in Russia between 1980 and 2005.

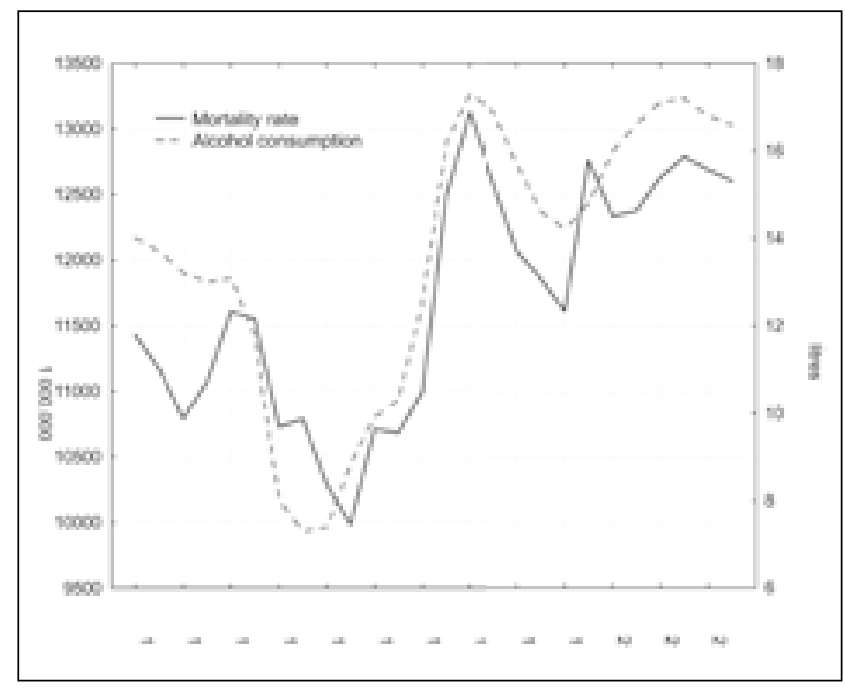

Figure 2. Trends in female all-cause mortality rate (right scale) and alcohol consumption per capita (left scale) in Russia between 1980 and 2005.

The specification of the bivariate ARIMA model and outcome of the analyses are presented in Table 1. According to the results, alcohol consumption is a statistically significant associated with both male and female all-cause mortality rates, implying that a 1-litre increase in per capita consumption is associated with an increase in male mortality of $3,9 \%$ and female mortality of 2,4\%. The estimated effect of alcohol consumption on the age-specific all-cause mortality rates for men ranged from 2,4\% (75+ age group) to $8,2 \%$ (30-44 age group) and for women from 1,6\% (75+ age group) to $6,3 \%$ (30-44 age group).

Table 1 shows the relative proportion of alcoholattributable deaths to all deaths by gender and age. The results of the analysis suggest that $41.1 \%$ of all male deaths 
Table 1. Estimated effects (bivariate ARIMA model) of overall alcohol consumption on all-cause mortality rates and estimation of alcohol-attributable fraction.

\begin{tabular}{lcccccccc}
\hline \multicolumn{1}{c}{ men } \\
\hline age & model & estimates & $P$ & AAF & model & estimates & $P$ & AAF \\
$15-29$ & $1,1,0$ & 0,057 & 0,000 & 0,539 & $1,1,0$ & 0,035 & 0,000 & 0,378 \\
$30-44$ & $1,1,0$ & 0,082 & 0,000 & 0,672 & $1,1,0$ & 0,063 & 0,000 & 0,575 \\
$45-59$ & $1,1,0$ & 0,059 & 0,000 & 0,551 & $1,1,0$ & 0,048 & 0,000 & 0,479 \\
$60-74$ & $1,1,0$ & 0,031 & 0,000 & 0,344 & $1,1,0$ & 0,021 & 0,000 & 0,248 \\
$75+$ & $1,1,0$ & 0,024 & 0,004 & 0,278 & $1,1,0$ & 0,016 & 0,004 & 0,195 \\
$15-75+$ & $1,1,0$ & 0,039 & 0,000 & 0,411 & $1,1,0$ & 0,024 & 0,000 & 0,278 \\
\hline
\end{tabular}

Note.

${ }^{a}$ asterisks under this column reflect statistical significance between cohorts (cocaine and heroin); $b$ asterisks under these columns reflect statistical significance between gender.

${ }^{*} \mathrm{P}<0.01 ;{ }^{* *} \mathrm{P}<0.005 ;{ }^{* * *} \mathrm{P}<0.001$

and $27,8 \%$ female deaths in Russia could be attributed to alcohol. The estimated AAF for men ranged from 27,8\% (75+ age group) to $67,2 \%$ (30-44 age group) and for women from $19,5 \%$ ( $75+$ age group) and 57,5\% (30-44 age group).

\section{Discussion}

According to the results there was a positive and statistically significant effect of per capita alcohol consumption on all-cause mortality in Russia. This research evidence clearly indicates that population drinking and mortality are positively related phenomena in Russia. It is of interest to compare present findings with results for other countries, where the drinking culture is characterized by heavy drinking episodes. The pooled effect estimated of $3.9 \%$ per litre close to previous findings, obtained for Northern Europe (3\% per litre) and stronger than the estimates for Mid- and South-European countries (1\% per litre) (Norström, 2001). In this context, it should be pointed out that recent time series analysis based on Russia data showed that the relationship between alcohol and mortality was stronger for sales of distilled spirits relative to the total level of alcohol sale (Razvodovsky, 2010b). Similarly, the large individuallevel study in the Russian Federation found a strong positive association between frequency of drinking vodka/frequency of binge drinking and all-cause mortality (Nicholson, Bobak, Murphy, Rose, \& Marmot, 2005). Taken together, these findings provide support for the binge drinking hypothesis, suggested that episodic heavy drinking of spirits is an important determinant of mortality crisis in Russia (Stickley, Razvodovsky, \& McKee, 2009; Nemtsov, Davydov, \& Razvodovsky, 2009).

Estimation the proportion of alcohol-attributable fraction suggests that $41,1 \%$ of male deaths and $27,8 \%$ of female deaths in Russia are attributable to alcohol. These estimates are comparable to findings from a case-control study in Izhevsk suggested that $43 \%$ of all deaths of male in the 25-54 years age range were attributed to hazardous drinking (Leon et al., 2007). A more recent study in the Siberian city of
Barnaul based on proxy information on alcohol consumption and other lifestyle factors from families of 48557 adults who died in 1990-2001 showed that alcohol was responsible for $59 \%$ of all male and 33\% of all female deaths at ages 15-54 years (Zaridze et al., 2008). The fact that the AAF estimated from aggregate-level data is similar to previous individuallevel estimates suggests that this method should give reliable estimates of alcohol-attributable deaths.

As it was already highlighted, males had considerably higher mortality burden than females. The harmful drinking might be responsible for the gender differences in alcohol attributable deaths. The population surveys from Russia show consistently higher rates of binge drinking among men than women. Indeed, the results of study carried out in Archangelsk suggest that $61.9 \%$ of male and $25.7 \%$ of female industrial workers had a consumption pattern that was hazardous according to the AUDIT definition (Nilssen et al, 2005).

The proportion of alcohol-attributable deaths varied widely between age groups, indicating the difference in alcohol consumption rate. As expected, young and middle age men had the largest proportion of alcohol-attributable deaths with more than half of all deaths attributed to alcohol. This reflects the fact that the level of alcohol-related problems among yang and middle age men is especially high. In principle, it's not surprisingly, given that the previous studies identified an unhealthy lifestyle among middle-age working class Russian males with the high level of alcohol consumption (Cockerham, 2006). Moreover, it's a harmful pattern of drinking featuring big doses of vodka in a short period of time with a small snack (Nemtsov, \& Razvodovsky, 2008). An analysis of frequency of drinking by male age groups indicates that the frequency climbs steadily to a peak between ages 30-39, before decreasing slightly in the 40-44 and 45-49 year-old and from age 50 declines significantly (Cockerham, 2006). A recent study based on the data from the Russian Longitudinal Monitoring Survey (RLMS) showed that frequent, heavy drinking was significantly more common amongst men aged 40-59 years than in older and younger men (Perlman, 2010).

Before concluding, it is necessary to address potential limitations of this study that may have affected the outcome. In particular, estimating unrecorded consumption of alcohol in Russia is a challenge, because of the diversity of this fraction of alcohol consumption that ranges from samogon through legal non-beverage alcohol (medical tincture) to counterfeit vodka produced from technical spirits (Razvodovsky, 2008). We relied on estimated overall level of alcohol consumption across the period. However, the accuracy of assessment of actual alcohol consumption using indirect methods depends significantly on whether the level of alcohol consumption is the only factor influencing the index chosen as the indicator of alcohol-related problems. This represents an essential drawback of such methods, because many other factors influence the level of alcoholrelated problems (Razvodovsky, 2010a).

Another potential source of bias is the influence of some omitted variables that is correlated with alcohol as 
well as mortality. Tobacco is a major risk factor for many causes of deaths and it is likely to be correlated with alcohol consumption (Peto et al., 1996). In his study based on Canadian data, Norstrom reported that estimated alcohol effect decreased from 2.9 to $1.7 \%$ per litre when tobacco was included in the model (Norström, 2004). However, in a recent time-series analysis it was highlighted that smoking as indicated from sales data did not have a significant impact on cardiovascular mortality in Russia (Ramstedt, 2009).

Finally, the estimates of AAF for women, where heavy drinking is restricted to a relatively small proportion of the population, gives rise to the suspicion of possible measurement error. It should be recognized that ignoring the confounding variables (unemployment, material deprivation, psychosocial stress, quality of health care) may imply that the alcohol effect is overestimated, leading to upward bias. Nevertheless, there are some indications that Russian women are drinking more now which is likely to be a factor in the narrowing of the male-female alcohol-related mortality rate ratio (Stickley et al., 2007). In his recent study, based on the results of RLMS Perlman highlighted that heavy frequent drinking almost doubled in women between 1994 and 2004 (Perlman, 2010). Furthermore, younger women drank more than their older counterparts, suggesting that more young women are adopting risky lifestyles.

In conclusion, these findings indicate that alcohol is a major contributor to the high mortality rate in Russian Federation. Therefore prevention of alcohol-attributable harm should be a major public health priority in Russia. Given the distribution of alcohol-related deaths with the highest proportion among the young and middle age men, in order to reduce alcohol-related health burden, interventions should be focused on the young and middle-aged. Recent history in Eastern Europe has shown that alcohol-attributable mortality can respond to alcohol availability control measures.

\section{Conflict of interest}

None declared.

\section{References}

Alanko, T. (1984). An overview of techniques and problems in the measurement of alcohol consumption. Research Advances in Alcohol and Drug Problems, 8, 209-226.

Anderson, P. P., \& Baumberg, B. (2006). Alcohol in Europe. London: Institute of Alcohol Studies.

Andreev, E., Pridemore, W.A., Shkolnikov, V.M., \& Antonova O.I. (2007). An investigating of the growing number of deaths of unidentified people in Russia. European Journal of Public Health, 18, 252-257.

Box, G. E. P., \& Jenkins, G.M. (1976). Time Series Analysis: forecasting and control. London: Holden-Day Inc.
Cockerham, C.W. (2006). Health lifestyle in Russia. Social Science \& Medicine, 51, 1313-1224.

Grant, M., \& Litvak, J. (1998). Drinking patterns and their consequences. Washington, DC: Taylor \& Francis.

Leon, D., Saburova, L., Tomkins, S., Andreev E., Kiryanov N., McKee M., \& Shkolnikov V. (2007). Hazardous alcohol drinking and premature mortality in Russia: a population based case-control study. Lancet, 369, 2001-2009.

Moskalewicz, J., Razvodovsky, Y., \& Wieczorek, P. (2009). East-West disparities in alcohol-related harm within European Union. Paper presented at the KBS Annual Conference, Copenhagen, 1-5 June, 2009.

Murray, C. J. L., Ezzati, M., Lopez, A. D., Rodgers, A., \& Hoorn, S. V. (2003). Comparative quantification of health risk: conceptual framework. Population Health Metrics, 1, 1-20.

Nemtsov, A.V. (2000). Estimates of total alcohol consumption in Russia, 1980-1994. Drug and Alcohol Dependence, 58, 133-142.

Nemtsov, A.V. (2002). Alcohol-related human losses in Russia in the 1980s and 1990s. Addiction, 97, 1413-1425.

Nemtsov, A.V., \& Razvodovsky, Y. E. (2008). Alcohol situation in Russia, 1980-2005. Social and Clinical Psychiatry, 2, 52-60.

Nemtsov, A.V., Davydov, K. E., \& Razvodovsky, Y. E. (2009). Comparative analysis of the alcohol situation in Belarus and Russia. Narcologia, 1,52-60.

Nicholson, A., Bobak, M., Murphy, M., Rose, R., \& Marmot, M. (2005). Alcohol consumption and increased mortality in Russian men and women: a cohort study based on the mortality of relatives. Bulletin of the World Health Organization, 83, 812-819.

Nilssen, O., Averina, M., Brenn, T., Brox, J., Kalinin, A., \& Archipovski, V. (2005). Alcohol consumption and its relation to risk factors for cardiovascular disease in the north-west of Russia: the Archangelsk study. International Journal of Epidemiology, 34, 781788.

Norström, T., \& Razvodovsky, Y. (2010). Per capita alcohol consumption and alcohol-related harm in Belarus, 1970-2005. European Journal of Public Health, 20, 564-568.

Norström, T., \& Skog 0. J. (2001). Alcohol and mortality: methodological and analytical issue in aggregate analysis. Addiction, 96, 5-17.

Norström, T. (1989). The use of aggregate data in alcohol epidemiology. British Journal of Addiction, 84, 969-977.

Norström, T. (2001). Per capita alcohol consumption and all-cause mortality in 14 European countries. Addiction, 96 (Suppl. 1), 113128.

Norström, T. (2004). Per capita alcohol consumption and all-cause mortality in Canada, 1950-98. Addiction, 99, 1274-1278.

Norström, T. (2006). Per capita alcohol consumption and all-cause mortality in Russia. In: Understanding choice, explaining behavior. Essays in honor of Ole-Jorgen Skog (pp. 211-223) Oslo: Academic Press. 
Perlman, F. J. A. (2010). Drinking in transition: trends in alcohol consumption in Russia 1994-2004. BMC Public Health, 10, 691.

Peto, R., Lopez, A.D., Boreham, J., Thun, M., Heath, C., \& Doll, R. (1996). Mortality from smoking worldwide. British Medical Bulletin, 52, 12-21.

Ramstedt, M. (2009). Fluctuations in male ischemic heart disease mortality in Russia 1959-1998: Assessing the importance of alcohol. Drug and Alcohol Review, 28, 390-395.

Razvodovsky, Y. E. (2008). Noncommercial alcohol in central and eastern Europe, ICAP Review 3. In: International Center for Alcohol Policies, ed. Noncommercial alcohol in three regions. Washington, DC: ICAP, 17-23.

Razvodovsky, Y. E. (2010a). Unrecorded alcohol consumption: quantitative methods of estimation. Alcoholism, 46, 15-24.

Razvodovsky, Y. E. (2010b). Beverage specific alcohol sale and mortality in Russia. Alcoholism, 46, 63-75.

Rehm, J., Sulkowska, U., Manczuk, M., Boffeta, P., Powles, J., Popova, S., \& Zatonski, W. (2007). Alcohol accounts for a high proportion of premature mortality in central and Eastern Europe. International Journal of Epidemiology, 36, 458-67.

Rehm, J., Taylor, B., \& Patra, J. (2006). Volume of alcohol consumption, pattern of drinking and burden of disease in the European region. Addiction, 101, 1086-95.

Stickley, A., Leinsalu, M., Andreew, E., Razvodovsky, Y. E., Vagero, D., \& McKee, M. (2007). Alcohol poisoning in Russia and the countries in the European part of the former Soviet Union, 1970-2002. European Journal of Public Health, 17, 444-449.

Stickley, A., Razvodovsky, Y., \& McKee, M. (2009). Alcohol mortality in Russia: A historical perspective. Public Health, 123, 20-26.

WHO. (2011). Global status report alcohol and health. Switzerland. WHO Press.

Zaridze, D., Maximovitch, D., Lazarev, A., Igitov, V., Boroda, A., Boreham, J., Boyle, P., Peto, R., \& Boffetta, P. (2008). Alcohol poisoning is a main determinant of recent mortality trends in Russia: evidence from a detailed analysis of mortality statistics and autopsies. International Journal of Epidemiology, 38, 143-153. 